\title{
The Exploration and Practice on Teaching of Inorganic Chemistry Experiment-Taking Zaozhuang University as an Example
}

\author{
Wentao $\mathrm{Yi}^{\mathrm{a}}$, Chunyan Yan ${ }^{\mathrm{b} *}$, Jie $\mathrm{Ma}^{\mathrm{c}}$, Yong Liu ${ }^{\mathrm{d}}$, Qiaoli Lin $^{\mathrm{e}}$ and Xiaoxia Wu ${ }^{\mathrm{f}}$ \\ College of Chemistry, Chemical Engineering and Materials Science, Zaozhuang University, \\ Zaozhuang 277160, China \\ aqislywt@163.com, bqislycy@163.com, c mara8637@163.com, \\ diuyong2049@126.com, ${ }^{\mathrm{e}} 18769241135 @ 163 . c o m,{ }^{f} 15263271752 @ 163 . c o m$
}

\begin{abstract}
Keywords: Inorganic chemistry experiment; Teaching reform; Exploration and practice; Curricular system; Teaching method
\end{abstract}

\begin{abstract}
Inorganic chemistry experiment is the first compulsory chemistry experiment course for chemistry, chemical engineering, applied chemistry and other chemistry related majors in colleges and universities. It plays an extremely important role in cultivating the good experimental habits of the students. Aiming at the problems existing in the teaching of traditional inorganic chemistry experiment, several aspects such as curricular teaching system, experimental teaching contents, experimental teaching methods, assessment methods of learning effect, opening laboratory were introduced from the point of view of the exploration and practice on inorganic chemistry experiment teaching, taking Zaozhuang University as an example. The aim is to exchange experience of inorganic chemistry experiment teaching reform with other universities' craft brother for learning and progress together.
\end{abstract}

\section{Introduction}

Inorganic chemistry experiment is a major basic course for the college freshmen. It is the continuation and deepening of the chemistry experiment in high schools, and it is also the basis for the follow-up experimental courses in colleges and universities. Through the laboratory training, the students will obtain lots of chemical information that is helpful for their learning of inorganic chemistry. They also gain experience of practical laboratory techniques and carry out chemical experiments, largely in connection with quantitative analysis and important chemical principles. In one hand, the learners will further understand the elementary theories and concepts of inorganic chemistry. On the other hand, the learners can train the primary skills for chemical experiments and be proficient in them, which can be helpful for their following study and investigation. It also lays a good foundation to cultivate the rigorous scientific attitude and good experimental quality for future study and work for the students. In all, inorganic chemistry experiment teaching can not only cultivate the freshmen's skills and science literacy, but also can develop their practical ability and innovation capability $[1,2]$.

However, in the teaching of inorganic chemistry experiment, students lacked learning interests and ability to integrate theory and practice and their experimental operation was not standardized normally because of the unreasonable teaching contents, assessment methods and obsolete teaching methods. In view of the situation, it is necessary to adjust the curriculum system of inorganic chemistry experiment, optimize the content of experiment, improve the teaching methods and assessment methods of learning effect so as to raise students' interest in learning inorganic chemistry experiment and improve students' ability to integrate theory with practice.

We want to cultivate the students majoring in chemistry or related specialties with $\mathrm{C}_{3} \mathrm{H}_{3}$ competences [3] (namely Clean Habit, Clear Head and Clever Hands) through the training of experiments. But how can we improve the teaching and learning effect of inorganic chemistry experiment? Inorganic chemistry experiment teaching reform in five aspects has been carried out and explored at Zaozhuang University, which has achieved good results as detailed in the following sections. 


\section{Establishing “Multi-Level” Inorganic Chemistry Experiment Teaching System}

The traditional experimental teaching system is usually composed of four basic experimental courses, which are set independently. Many class hours and contents repetition render the students little interest in the experiment. Through integration and optimization of experiment contents, experimental class hours are reduced, and the experiment contents are divided into four levels, namely the basic experiment, comprehensive experiment, designing experiment and research experiment, whose contents come from practical applications. The repeated and confirmatory experiments are reduced, and the comprehensive experiments along with the basic operation are emphasized, so as to improve the students' activeness and enthusiasm in learning, and thus the raising of teaching quality. The proportion of the four kinds of experiments is about $30 \%$ basic experiments, $50 \%$ comprehensive experiments, $10 \%$ design experiments, and $10 \%$ research experiments. At the same time, the knowledge of green chemistry and chemical safety runs through the entire experiment process, so as to cultivate the environmental and safety awareness of the students. For example, the experimental waste must be recovered, classified and disposed together, never discharged directly. Every student entering in the lab must wears protecting glasses and lab-gown. Micro and semi-micro amount experiments were carried out to replace constant experiments, in order to save chemicals and reduce environmental pollution.

The primary purpose of the basic experiment is the basic operation and the training of basic experimental skills. The main aim of the comprehensive experiment is to improve students' experimental skills and accomplishments. The main aim of the design experiment is to strengthen students' abilities to apply various experimental techniques, methods and instruments. The main aim of the research experiment is to cultivate students' abilities for design, comprehensive thinking and innovation. The experimental content of each level has different teaching tasks, however, they are relatively independent and interconnected with each other. The teaching concepts of "Multi-level" inorganic chemistry experiment teaching system are more advanced and scientific. Its experimental curriculum system structure is more reasonable and clear. And its teaching contents are more practical and objective, which can raise the learning interests of the students. This kind of experiment teaching system reflects the basic law of chemistry experiment teaching, and lays the solid foundation to promote the quality education and cultivate the innovative talents of chemistry.

\section{Reforming Experimental Teaching Methods and Means}

Previewing is an important part of inorganic chemistry experiment, which determines the success or failure of an experiment, and directly influences the formation of students' abilities. So each student must refer to the literature and preview the experiment to be done before the experiment in order to be familiar with the experiment content. Otherwise, they will not be allowed into the lab. After the collective learning and discussion on the experiment by the teacher and the students together, the students begin to do the experiment. In order to improve students' interest in experiment and stimulate students' enthusiasm for learning, our teaching team has tried to introduce multimedia teaching into the experiment teaching process. Through the video teaching, students can observe and understand the experiment from multiple directions and multiple angles. Multimedia teaching is adopted as far as possible especially for those experiments with toxic, pollutional or dangerous contents and steps. Environment protecting awareness permeates all aspects of experimental teaching. While the basic operation and skill training of inorganic chemistry experiments are carried out by repeated practice and increase of the experimental hours to ensure the standardized experimental skills. The students' learning enthusiasm and interest are improved, and the good interaction between teaching and learning are formed through the combination of multimedia teaching and teachers' explanation. At the same time, heuristic experiment teaching mode is also introduced into the class to guide the students to think deeply. Teachers will combine the knowledge of inorganic chemistry theory with the relevant content of experiment so as to strengthen the memory, deepen understanding and application, and cultivate students' comprehensive ability. Each experiment will be done by one student independently as much as possible to exercise the basic 
experimental skills of the students fully. The teachers will track, guide and supervise in the whole experimental process to find and solve problems timely. The teachers will give each student a score according to their individual operation to improve the students' self-consciousness and initiative. In the course of experimental teaching, the combined way by the individual guidance and collective explanation is adopted. For incorrect experimental operations, the teachers can correct them timely. For the phenomena that the students do not understand, the teachers will solve, communicate with the students timely. Thus, it solves not only the teaching problem, but also the relationship between teachers and students.

\section{Establishing the Comprehensive Assessment Method of Inorganic Chemistry Experiment}

The traditional evaluation method for inorganic chemistry experiment is monotonous and one-sided, which cannot reflects the students' performance comprehensively and objectively. The scientific and comprehensive assessment system is urgently need to established, which should focus on the students' ability to operate and solve problems. Thus, the comprehensive assessment method of inorganic chemistry experiment at Zaozhuang University is explored and constructed, which divides students' term grades into three parts: basic operation scores (40\%), experiment report scores (30\%) and experiment theoretical examination scores( $30 \%$ ). If the result of one single item is unqualified, the total result is not qualified. We have established a perfect exam-question-bank and the accurate, reasonable scoring standard with strong operability. In the exam, the test questions are randomly selected from the exam-question-bank, and the practice of the teaching-exam separation is carried out. This kind of assessment method can effectively urge the students to take each experiment link seriously, realizing the purpose of cultivating comprehensive experimental skills of the students.

The basic operation scores is given by the teacher in the course of the experiment, mainly on the basis of operation correctness, the standardization of instrument usage, the record of experimental phenomena and data, the situation of tabletop instruments, etc. At the end of semester, the basic operation results of the experiments (often 10 or 12 in one semester) in this semester are added and the average score is obtained. The scores of the experiment report are made up two parts, i.e. the scores of the experiment report and preview report of the students. We have increased the proportion of the results of the preview report purposively, urging the students to pay more attention to the pre-study process. Experiment theory exam emphasizes on the comprehensive ability to solve problems and innovation. We try to increase the content of a variety of experimental design related to practical application, in order to promote the improvement of the students' problem-solving ability. Such a variety of assessment method can evaluate the students' hands-on ability and innovative ability truthfully.

\section{Implementation of Opening-Lab Teaching Mode}

Opening teaching, a new teaching idea, regards the promotion of people's development as the focus and create a more open, interactive, independent learning environment for students based on the professional knowledge of teaching [4]. In the opening teaching environment, students' ability of autonomous learning and inquiry can more fully developed, so as to achieve overall development goal of the comprehensive quality. The opening laboratory teaching mode is an important means to cultivate the innovative and applied talents. The implementation of the opening laboratory provides a good experimental environment for students to do exercise on basic operation or do some research. On the one hand, students who like chemical experiment or research have more opportunities to engage in chemical practice activities. On the other hand, students with poor hand skills are more likely to exercise at extracurricular time. We have attempted to open lab in the aspects of experimental contents, time and management. The basic knowledge is understood and mastered through the opening planned basic teaching experiments, and the initial sense of innovation and creativity are trained through the opening comprehensive experiments. And then the ability of analyzing and solving problem and innovation are improved through the opening lab, thus the 
innovation consciousness and capability of the students are trained progressively.

Except for normal teaching time, the rest of the time is open to students. Students can make appointments in advance and do scientific research activities in the lab on time. We also developed a strict system of opening laboratory management rules and regulations and lab safety, which can not only protect the enthusiasm of students to carry out scientific research activities and the cultivation of innovation ability, but ensure the normal operation of large experimental apparatus, and fully improve the efficiency of experiments. The management system, the establishment of an open lab fund (often in the form of Student Research Training Program) and the supervisor responsible system explored at Zaozhuang University provide a strong guarantee for the education of students' innovation consciousness and ability.

\section{Organizing Experimental Skills Competition}

In order to improve students' basic experimental skills, stimulate students' interest in learning, the basic skills experimental competition was organized regularly in Zaozhuang University, often once a year. Strict competition system and scoring criteria were set up in advance scientifically.

Every student can participate in the competition. According to the method of drawing lots, the students strictly follow the experimental operation requirements, and record the results correctly according to the contents of the experiment. The judge teachers judge each contestant according to their operation ability and the ability to solve problems, and finally select the first prize, the second prize and third prize winner according to strict criteria. Every year, the selected students participate in the extracurricular academic science and technology competition and chemistry experiment skills competition of Shandong province. The results were satisfied in recent years. The successful conduction of these activities and achievements have led to an unprecedented enthusiasm for scientific research of the students, which has opened up a feasible way for the cultivation of new innovative talents adapting to the needs of society.

\section{Summary}

The curricular teaching system, teaching contents, teaching methods, assessment methods, opening laboratory of inorganic chemistry experiment course was explored and put into practice at Zaozhuang University. The inorganic chemistry experiment teaching reform emphasizes on the fundamentality of inorganic experiments and highlights the innovation of experiments, which is helpful to arouse the enthusiasm and initiative of student, to cultivate students' ability to analyze and solve problems. It provides a broad stage to cultivate students' innovative consciousness and innovative ability.

\section{Acknowledgements}

This research was financially supported by the Teaching Reform Program of Zaozhuang University (2017013).

\section{References}

[1] Y. Liu, Q. Zou, C. L. Fang, et al, Reform and Innovation of experiment Teaching of Inorganic Chemistry, Experiment Science and Technology, 14(2016)140-145.

[2] Z. H. Jing, B. P. Ling, M. Sun, et al. Exploration inorganic chemistry experiment teaching reform, Laboratory Science, 17(2014)81-83.

[3] G. M. Bai, X. Y. Wang, S. Z. Liu, Reforming inorganic chemistry experiment teaching, cultivating the making of $\mathrm{C}_{3} \mathrm{H}_{3}$ of students, Research and Exploration in Laboratory, 31(2012)114-116. (in Chinese)

[4] X. L. Ma, X. D. Liu, C. Y. Yang, et al, Study and practice of open teaching model in chemistry experiment, Laboratory Science, 14(2011)183-186. 